\title{
Empirical Research on the Cultivation of Primary School Students' Computational Thinking Based on Visual Programming - - Take "Codemao" Platform Teaching as an Example
}

\author{
Hongmei Wang \\ Caijia Campus, Renmin Road Primary School, Chongqing, China
}

\begin{abstract}
With the rapid development of science and technology, cultivating primary school students' computational thinking ability is one of the most important tasks in contemporary education. Visual programming is closely related to computational thinking. Based on expounding their connotations and characteristics, this paper first analyzes the problems existing in the training of primary school students' computational thinking, then further constructs the training mode of primary school students' computational thinking based on visual programming and conducts classroom teaching practice research, finally puts forward suggestions on the training of primary school students' computational thinking based on visual programming, and provides effective practical guidance for training primary school students' computational thinking ability, innovation and problem-solving ability.
\end{abstract}

Key words: visual programming; computational thinking; cultivation strategy; kitten

\section{Visual Programming and Computational Thinking}

\subsection{Connotation and characteristics of visual programming}

In the field of computer science, programming is a process in which program codes are written with a computer's special programming language to solve a certain problem, and the corresponding results are finally obtained. Visual programming is produced by the combination of visualization and programming, and it is a brand-new programming language. It gets rid of abstract and tedious programming language and enables younger children to write programs through the intuitive operation. The advantages of visual programming are mainly reflected in the following aspects. First, the intuitive operation and interesting experience of visual programming can effectively enhance students' interest in learning. Second, simplified programming logic can speed up development and avoid tedious syntax debugging. Third, reducing the basic technical threshold such as code statement writing can effectively focus on the cultivation of Computational Thinking and the development of ability.

\subsection{Connotation and characteristics of computational thinking}

In recent years, the value and significance of computational thinking have become increasingly prominent, and it has become a hot topic that the current international education and computer circles are paying attention to. Regarding the 
connotation and characteristics of computational thinking, there have always been divergent opinions in academia, and there is no unified conclusion. After a large number of literature studies, the author summarized the opinions and research results of the predecessors and summarized the computational thinking methods and connotations defined by more authoritative scholars and institutions. As shown in Table 1.

Table 1. Summary of computational thinking methods and connotation

\begin{tabular}{|c|c|}
\hline Wing(2011) & $\begin{array}{l}\text { Reduction, embedding, transformation, simulation, recursion, parallelism, } \\
\text { abstraction, decomposition, modeling, prevention, etc. }\end{array}$ \\
\hline $\begin{array}{l}\text { Brennan K \& Resnick M } \\
\text { (2012) }\end{array}$ & $\begin{array}{c}\text { Incremental and repetitive, testing and debugging, reuse and re-creation, abstraction } \\
\text { and modularization }\end{array}$ \\
\hline $\begin{array}{c}\text { International } \\
\text { Educational Technology } \\
\text { Association (ISTS) and } \\
\text { Computer Science } \\
\text { Teachers Association } \\
\text { (CSTA) (2018) }\end{array}$ & $\begin{array}{l}\text { Data collection, data analysis, data characterization, problem decomposition, } \\
\text { abstraction, algorithms and procedures, etc. }\end{array}$ \\
\hline $\begin{array}{c}\text { Google's Exploring } \\
\text { Computational Thinking } \\
\text { (ETC) project }\end{array}$ & $\begin{array}{l}\text { Abstraction, algorithm design, automation, data collection, data analysis, data } \\
\text { representation, decomposition, parallelization, etc. }\end{array}$ \\
\hline $\begin{array}{l}\text { Guoliang Chen and } \\
\text { Dong Rongsheng (2013) }\end{array}$ & $\begin{array}{c}\text { Calculation, abstraction, automation, design, communication, collaboration, } \\
\text { memory, evaluation }\end{array}$ \\
\hline
\end{tabular}

Primary school is the initial stage of computational thinking training, and the third grade is the starting point for training. Students in the third grade and above have certain generalization ability and reasoning ability. They start from the level of image generalization to the level of abstract generalization. At this time, they also begin to have the ability to combine and classify, and they can independently, well-founded, and clearly demonstrate some more complicated probabilistic judgments. Through the above analysis of the cognitive characteristics of primary school students, we have discovered the peculiarities of primary school students' thinking and cognition. These peculiarities are an important reference for us to determine which computational thinking abilities primary school students should master.

\section{The Construction of Computational Thinking Training Model for Primary School Students} Based on Visual Programming

According to the above description of computational thinking, the cultivation of computational thinking is mainly based on the point of view that conforms to the cognitive characteristics of primary school students and focuses on the elements of computational thinking that primary school students can master: data processing (data collection, analysis, and presentation), abstraction (transformation and attention separation point), automation (algorithmic thinking and error correction/debugging), evaluation. In the process of cultivating elementary school students' computational thinking teaching, students are the main body, and teachers as facilitators inspire students to explore and innovate designs, and continuously improve students' computational thinking ability in hands-on operations. The computational thinking training model is shown in Figure 1. 


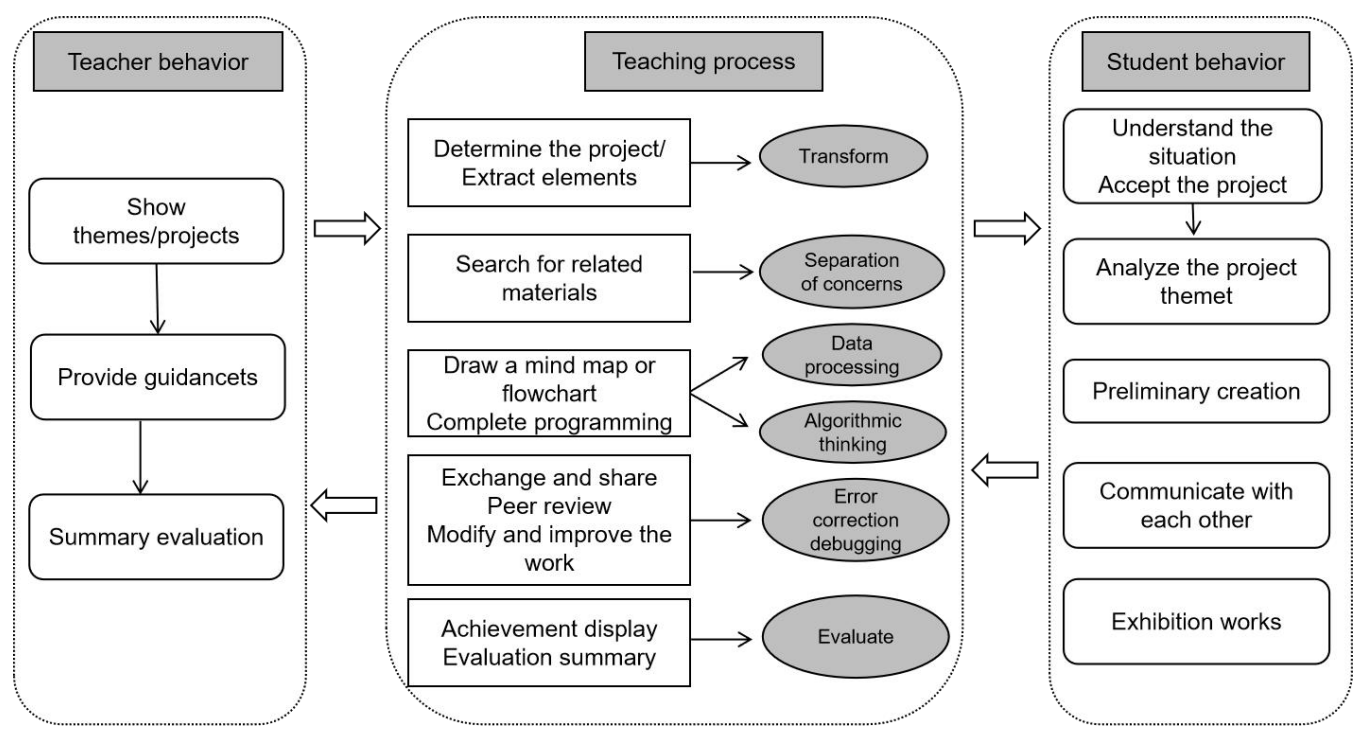

Figure 1. The model of cultivating primary school students' computational thinking

According to the training model of primary school students' computational thinking, each link of the teaching process is closely related to the various dimensions of computational thinking. In terms of abstraction, transformation is to reinterpret a complex situational problem, and finally, it can be abstracted into a model with a clear corresponding algorithm and instruction solution. Focusing on the separation point (problem decomposition) is to reasonably decompose complex problems. In terms of automation, algorithmic thinking is based on abstraction, using symbols (building blocks) to express problems and seek efficient algorithms to solve the problems and implement them. In the process of error correction/debugging, find and correct the failures in your design or implementation when you solve a specific problem, change various parameters to further innovate your work, so that you can successfully achieve the goal of solving the problem. In terms of evaluation, evaluate and think about the completed work to see if it has successfully solved the problem.

\section{Cases of Cultivating Computational Thinking Ability Based on Visual Programming}

3.1 Create situation and display project

\subsubsection{Topic items: smart Beibei}

Express and promote Beibei's famous scenic spots, specialty snacks, and celebrities through programming works.

\subsubsection{Programming tools}

"Kitten" is currently the more popular graphical children's programming software in China. It has features such as low technical threshold, building blocks style, drag-and-drop programming methods, etc., which are suitable for the age characteristics of primary school students. It is also the main tool for the promotion of programming education in primary and secondary schools in China.

\subsection{Achievement display, evaluation summary}

3.2.1 Strengthening the cultivation of students' computational thinking

A project contains many programs. Based on the basic knowledge of programming and graphical programming, students should learn project analysis-decomposition-combination, learn to draw mind maps and flowcharts, strengthen programming thinking, integrate algorithm knowledge, and cultivate self-learning ability and the ability to complete projects independently. In teaching, teachers train students to plan independently, improve design ability, and improve selfdisplay and expression ability. The mind map drawn by the students is shown in Figure 2. 


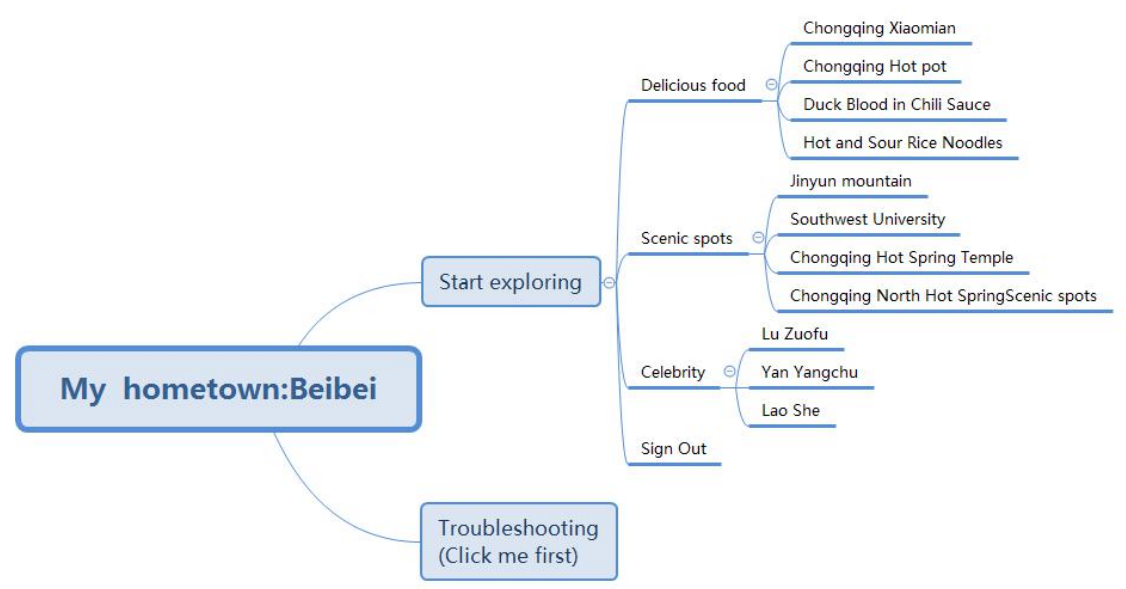

Figure 2. The mind map drawn by the student

\subsubsection{Inspire students to independently innovate design and research}

In the primary school students' creative computational thinking training model, students are inspired to create, and the creative process focuses on the cultivation of students' computational thinking, the selection of materials, creative ideas, and the solution of difficult problems. Achievement display, when analyzing and evaluating student works, starts from the design standards for evaluation and re-innovation creation. For example, the program design steps are clear, the structure is rigorous and reasonable, the code is standardized, the program design is innovative, and the function is diverse, etc.

\subsubsection{Cultivate students' innovative consciousness and ability}

Programming is the process of how to continuously divide big problems into small ones. In this process, students must think about how to reasonably arrange the code in the entire program, so that the program can smoothly process input, output, and other operations, which will greatly improve the students' logical analysis ability. For the same programming problem, different students will come up with different solutions, that is, students have different programming methods, so it is very likely that some students will come up with some novels and ingenious algorithm ideas, which will help cultivate their innovative consciousness and innovative ability.

\section{Summary and reflection}

After research on teaching practice, the author puts forward the following reference suggestions for the implementation process of computational thinking training.

4.1 Use visual learning tools to assist in cultivating computational thinking

Visual learning tools include mind maps, flowcharts, sketches by shots, etc. The use of these tools can help students complete problem analysis, decomposition, abstraction, and concrete reflection of thinking, and play an auxiliary role in the cultivation of computational thinking.

4.2 Pay attention to the gradual progress of the training process

The cultivation of computational thinking is a long-term process, especially under the premise that some inherent thinking of students has been formed, we cannot expect students to develop computational thinking in a short period time. Therefore, more attention should be paid to the gradual and orderly development of the training process. In the early stage, guidance and demonstration are the mainstay. The demonstration does not mean a specific work imitating, but a demonstration of a problem-solving process for students.

4.3 Use information resources flexibly to optimize teaching and realize personalized learning 
In the process of cultivating computational thinking, the flexible use of information resources can make efficiency more effective. For example, use major network resources such as the CodeMao, Kada, WeChat public account (Scratch), Bilibili station ((programming teacher) and other major network resources to push video resources according to the level of students' ability, and use the website platform to broaden students' creative ideas and break limitations. The creative work uses mind maps to repeatedly train students' ability to separate concerns.

\section{Conflicts of Interest}

The author declares no conflicts of interest regarding the publication of this paper.

\section{References}

[1] Wing, J.M. (2006). Computational thinking. Acm Sigcse Bulletin, 49(3):33-35.

[2] Wing, J M. (2011). Research Notebook: Computational Thinking What and Why? The Magazine of the Carnegie Mellon University School of Computer Science.

[3] Brennan K, Resnick M. (2012). New Frameworks for Studying and Assessing the Development of Computational Thinking. The 2012 Annual Meeting of the American Educational Research Association, 1-25.

[4] Yu X.H., Xiao M., Wang M.L. (2018). Computational Thinking Training in Progress: Practical Methods and Evaluation at the K-12 Stage. Journal of Distance Education, (02):18-28.

[5] Chen G.L., Chen R.S. (2013). The Expression System of Computational Thinking. China University Teaching, (12):22-26.

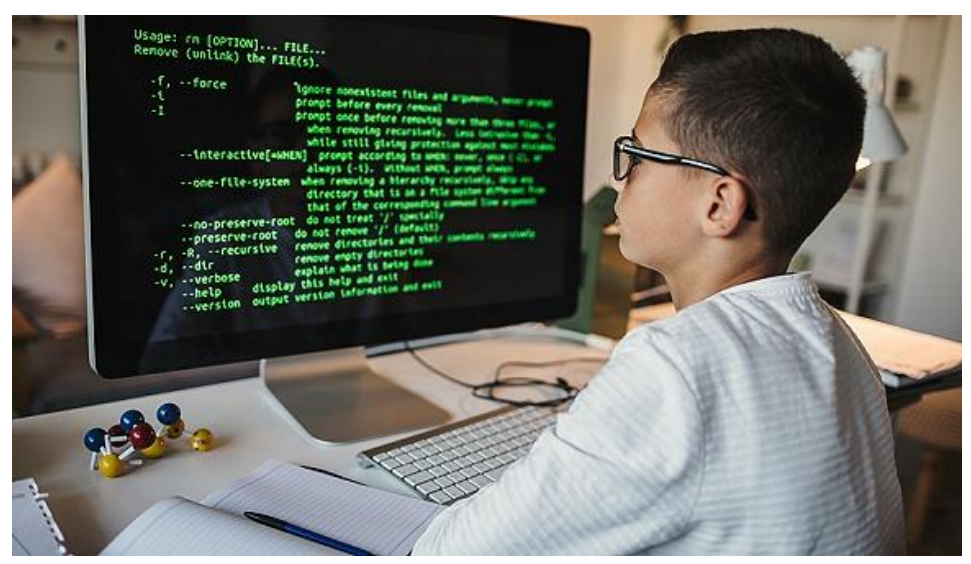

